\title{
VOLVIENDO A PENSAR LA EDAD DEL HIERRO (1)
}

\author{
RETHINKING THE IRON AGE
}

\author{
J. D. HILL y C. G. CUMBERPATCH (*)
}

\section{RESUMEN}

Este artículo defiende la urgente necesidad de evaluar críticamente las asunciones básicas manejadas por los arqueólogos de la Edad del Hierro en toda Europa. Sugiere que los marcos explicativos e interpretativos existentes son, en el mejor de los casos, inadecuados para comprender la evidencia arqueológica real sobre el período. En el peor, están reproduciendo todavía las ideologías nacionalistas y racistas decimonónicas (p. e. las preocupaciones por los "Celtas", los "Iberos", etc.). A partir de ejemplos de Gran Bretaña, y las Repúblicas Checa y Eslovaca, sostenemos que la evidencia arqueológica sobre la Edad del Hierro claramente no encaja con nuestras suposiciones modernas y eurocéntricas sobre lo que el período debería haber sido. Se sugiere que la arqueología de la Edad del Hierro tiene que reconocer la diferencia del pasado, el hecho de que las sociedades prehistóricas en Europa pudieron haber tenido formas de organización social, visiones del mundo y economías muy diferentes a las de la Historia europea posterior. Esto significa la puesta en cuestión crítica de la evidencia arqueológica y estar abierto a la posibilidad de que las interpretaciones existentes sean erróneas (p. e. recalcando el impacto de la Economía Mundial Mediterránea, el que los Oppida eran centros urbanos, o que los datos del poblamiento y subsistencia puede ser comprendidos de manera adecuada en términos capitalistas/funcionalistas modernos, etc.). Los estudios de la Edad del Hierro, en cuanto tales, sólo pueden ser una "Arqueología Contextual".

(1) Traducido por M.* Isabel Martínez Navarrete y revisado por los autores.

(*) University of Cambridge. Faculty of Archeology and Anthropology. United Kingdom.

\section{ABSTRACT}

This paper argues there is an urgent need to critically evaluate the basic assumptions used by Iron Age archaeologists across Europe. It suggests that the existing frameworks of explanation and interpretation are at best inadequate to understand the actual archaeological evidence for the period. At worst they are still unconsciously reproducing nineteenth century nationalist and racist ideologies (e. g. the preoccupations with the "Celts" or "Iberians", etc.). Drawing on examples from Britain, and the Czech and Slovak republics. we will argue that archaeological evidence from the Iron Age does not neatly fit our modernist and Eurocentric assumptions about what the period ought to have been like. It suggests Iron Age archaeology must recognise the difference of the past. that prehistoric societies in Europe may have had very different forms of social organisations, world views and economies than those in later European history. This means critically questioning archaeological evidence and being open to the possibility that existing interpretations are wrong (e. $g$. stressing the impact of the Mediterranean World Economy. that Oppidas were urban centres, or that settlement and subsistence data can be adequately understood in modern capitalist/functionalist terms, etc.). As such Iron Age studies can only be a "Contextual Archaeology".

Palabras clave: Edad del Hierro. Celtas. Vida diaria. Eurocentrismo. Arqueología Contextual. La especificidad del pasado.

Key words: Iron Age. Celts. Everyday Life. Eurocentrisin. Contextual Archaeology. The Difference of the Past. 


\section{INTRODUCCION}

¡La Edad del Hierro es aburrida, sobre todo si la comparamos con los períodos más antiguos de la Prehistoria, que son estimulantes $\mathrm{y}$ apasionantes!

Esta reacción ante el estudio de la Edad del Hierro europea, común entre los estudiantes, ilustra el abismo existente entre los distintos enfoques británicos en Prehistoria, y resulta particularmente clara al contrastar los objetivos, enfoques y asunciones empleadas por los autores británicos en el estudio de las Edades del Neolítico/Bronce con sus equivalentes en el de la Edad del Hierro. Aunque los enfoques de la Prehistoria en su conjunto se trastocaron durante los sesenta, sólo los correspondientes a las primeras perdieron realmente su inocencia (Clarke, 1973), y han continuado participando en una gran variedad de debates teóricos durante las dos últimas décadas, y siendo transformados por ellos. En este artículo intentaremos averiguar qué se esconde bajo esta fractura, y sostendremos que los estudios sobre la Edad del Hierro sólo pueden revitalizarse mediante un proceso de evaluación crítica, de auto-examen y de empleo de ideas que son moneda corriente en el estudio de la Prehistoria más antigua. Semejante cambio de percepción es vital, si queremos sacar todo el partido posible a la amplia base de datos accesible a los arqueólogos de la Edad del Hierro, un volumen de material mayor que el que ha promovido una variedad de interpretaciones tan amplia como la que se refiere a los períodos más antiguos de la Prehistoria.

La perspectiva adoptada en este trabajo puede ser descrita como específicamente británica en cuanto a su orientación, y nuestra intención es contribuir a un debate mutuamente beneficioso con otras escuelas nacionales y regionales de Arqueología.

El tema de la diferencia es central para el objetivo de este artículo. El pasado puede ser conceptualizado de formas muy variadas, muy habitualmente como "el mismo" o "el otro" (Ricoeur, 1981; Thomas, 1990). Lo característico es ver al Neolítico como diferente, otro $y$, consiguientemente, como problemático. En contraste, la Edad del Hierro queda representada como segura, "céltica", no problemática y "fa- miliar" (p. ej. Burl, 1981: 212; Miles, 1986: 55). ¿Pero, realmente este es el caso?

Al considerar esta cuestión es esencial centrarse en cómo los períodos prehistóricos han sido imaginados, exponer las asunciones raramente articuladas y las ideas preconcebidas que se esconden en el trabajo de los arqueólogos, y establecer así una arqueología reflexiva y autocrítica (Shanks y Tilley, 1987). Esto no lo concebimos solamente como una reflexión trascendental, sino también como un estímulo para un examen crítico de nuestra propia historia de la disciplina. Argumentaremos que los arqueólogos que estudian la Edad del Hierro deberían prestar mucha atención a los desarrollos recientes en los estudios sobre el Neolítico y la Edad del Bronce donde nociones tales como ideología, hábito, deposición estructurada y contexto han generado poderosos y nuevos enfoques para nuestra comprensión del registro arqueológico. Con todo, esto no significa recetar ciégamente estos métodos, terminologías u orientaciones; significa más bien inducir la adopción de una predisposición favorable de ánimo que debe aparecer cuando, al intentar usar el registro arqueológico para aprender sobre el pasado, nos enfrentamos con la posibilidad de un pasado muy diferente de aquél que nuestro sentido común esperaba o permitía. Esta no ha sido una característica de la arqueología de la Edad del Hierro ni en Gran Bretaña, ni en ningún otro lugar de Europa.

La necesidad de una Arqueología más crítica y auto-consciente ha ganado terreno a partir de algunas críticas recientes a la forma como los arqueólogos europeos han concebido el pasado, o han escrito sobre él (Shanks y Tilley, 1987; Hodder, 1991) y esto es particularmente aplicable al caso de la Prehistoria final (Rowlands, 1986, 1987; Hill, 1989; Cumberpatch, 1991). Ha habido una marcada tendencia a asumir una cierta universalidad de experiencia que ha tenido el efecto de crear una visión del pasado durante nuestra Edad del Hierro, según la cual, compartíamos esas características únicas que se adscriben a la Europa moderna. Este es un pasado europeo al que nuestros valores socio-culturales históricamente específicos y nuestras nociones de sentido común se consideran aplicables, en resumen, un pasado familiar. En el actual clima ideológico, la escritura de tales 
pasados debería ser reconocida como el acto abiertamente político que es (cf. Dennell, en prensa).

Para los practicantes de la arqueología desafiar la imposición de semejante pasado significa reconocer tanto la diferencia representada en el registro arqueológico como su propia capacidad para hablar acerca de la realidad pasada en su conjunto, y no simplemente sobre temas tales como subsistencia e intercambio. Un enfoque de este tipo en Arqueología tampoco debe ser un simple ejercicio de enamoramiento narcisista que signifique nada más que una proyección de las preocupaciones actuales al pasado. El registro arqueológico a menudo es lo suficientemente completo para permitir un diálogo entre pasado y presente, teoría y datos. Pero un diálogo es un asunto de doble dirección e implica dirigirse a alguien más que a uno mismo (Bradley, 1986: 748; Rowlands, 1986: 745-746; Shanks y Tilley, 1987: 104).

Esto es concebir la Arqueología como un ejercicio hermenéutico, en el que la comprensión emerge dentro de un círculo o espiral, una oscilación constante de proyección:corrección, parte:todo, el mismo: el otro, presente:pasado (Shanks y Tilley, 1987: 103-114). No se trata de defender un modelo de contrastación, una metodología científica como la sugerida para la arqueología de la Edad del Hierro (y muchas otras) en los últimos veinte años. Los intentos de separar "los hechos" de "la interpretación" llevan o a la esterilidad de una recolección obsesiva de datos, el destino de gran parte de la Arqueología en la tradición alemana (Collis, 1984; Cumberpatch, 1991), o a la perpetuación de unas explicaciones inocentes, basadas en el sentido común y, en último término, etnocéntricas para fenómenos culturales complejos. Una Arqueología reflexiva y crítica enfrenta esta cuestión intentando examinar el silencioso "otro no escrito" del texto arqueológico.

Concebir la Arqueología como una disciplina en la tradición hermenéutica (Bauman, 1978; Hodder, 1991) no es considerarla simplemente descriptiva sino, sobre todo, prescriptiva, permitiendo la identificación de los problemas y debilidades operantes en el círculo hermeneútico. Históricamente, en gran parte de Europa, la arqueología de la Edad del Hierro ha permitido que dominara el diálogo unidireccional entre uno mismo:el otro, el todo:la parte. El diálogo entre el todo:la parte es concebido como un asunto unidireccional, donde las interpretaciones están determinadas de arriba abajo. Como en la estructura piramidal de los modelos tradicionales de la sociedad "céltica" y de su poblamiento jerarquizado (p. ej. Cunliffe, 1986: 169), las partes están determinadas por el todo. Los estudios adicionales de tales partes (religión, trabajo del metal, cría de ganado, etc) sirven para colorear, para rellenar lo que ya se sabe; raras veces está permitido poner en cuestión la ortodoxia establecida. Igualmente, la relación paradójica entre presente:pasado, identidad:diferencia tiene un lado mutilado, es un diálogo donde raramente se permite la contribución del pasado como diferencia.

Dado que podemos reflexionar críticamente sobre nuestras propias asunciones, ¿por qué los arqueólogos de la Edad del Hierro no lo hemos hecho? Quizá es porque, cuando leemos el pasado distante, nunca estamos libres de nuestros pasados personales, somos miembros de una tradición académica e intelectual a pesar de nuestra consciencia de élla o nuestro deseo de adoptar una posición radical en relación con élla. Participamos de una forma de ver, hacer y decir que constituye una parte de nuestra cultura $y$, a través de nuestra participación, la perpetuamos. Nuestra actitud no hace nada por cambiar el poder que los pasados estudios acerca de La Edad del Hierro tienen sobre nosotros. No podemos salir de nosotros mismos y programarnos de nuevo, aunque sólo sea porque dependemos de datos recogidos y, lo que es más importante, de definiciones del tema creadas en el pasado. Las tradiciones sin embargo no son inmóviles y podemos reflexionar sobre los supuestos a través de los cuales estudiamos la Edad del Hierro y evaluarlos críticamente y, al hacerlo así, podemos aprender a entender y a expresar el pasado de nuevo. Pero, ¿por qué nuestra tradición ha sido más conservadora que radical? Es por una familiaridad que «sutilmente convierte lo anticipado en inevitable, en aceptable" (Shils, 1981: 198).

Tal familiaridad en la arqueología de la Edad del Hierro tiene un impacto que es doble; una relación incestuosa de familiaridad al concebir la Edad del Hierro como familiar. 


\section{LA EDAD DEL HIERRO FAMILIAR}

En el resto del artículo examinaremos algunas de las suposiciones variadas pero interconectadas que han estructurado la arqueología de la Edad del Hierro mediante una interrelación a menudo confusa y autorreferenciada de sentido común y "pseudohechos" (2) (Millett, 1990: XVI) para producir un pasado familiar y seguro. Algunos autores (Collis, 1984; Champion, 1987; Merriman, 1987; Cumberpatch, 1989; Taylor, 1991) las han criticado de modo efectivo, enfatizando la importancia que tiene en éllas una visión histórica del período que subraya una continuidad linear con el pasado. Es una arqueología que ha proporcionado descripciones que son, primero y sobre todo, históricas, que enfatizan la proximidad cronológica de los períodos "históricos" posteriores, unas cuantas referencias literarias dispersas, un sentimiento de que muchos de nosotros descendemos directamente de las gentes de la Edad del Hierro y, sobre todo, la imagen familiar de los "Celtas" (Chapman, 1992).

Los estudios "célticos" y de la Edad del Hierro prerromana han sido, en gran medida, sinónimos desde el comienzo del siglo XVIII, con la consecuencia de que los arqueólogos de la Edad del Hierro sólo recientemente han comenzado a poner en cuestión esa identificación, e incluso hoy en día dicha actitud está todavía restringida a una minoría. Esto quiere decir que nuestros yacimientos y textos raramente están habitados por "gente de la Edad del Hierro" sino por "Celtas", pueblos que resultan compartir no sólo la misma lengua, sino también la misma organización social, religión, espíritu y esencia.

Los "Celtas" nos son inmediatamente familiares y su sombra borra la diferencia en la Edad del Hierro. Su creación debe mucho a las tensiones y confusión en Europa a mediados y finales del siglo XIX y a su apropiación, quizá sin igual, por una colección diversa de ideologías, incluyendo el individualismo y el Romanticismo, el nacionalismo y el imperialismo.

Para grupos minoritarios en las Islas Británicas, como los galeses, irlandeses y escoceses, representaron a los antepasados que fueron

(2) Nota de la traductora: "factoids" en el texto original.

T. P.. $\mathrm{n}^{2} 50,1993$ capaces de vivir libres del yugo anglo-sajón, mientras que para los ingleses fueron, bajo la denominación de antiguos britanos, los defensores de la isla contra el imperialismo romano. Como el autor de novelas de aventura, G. A. Henty, hizo notar en "Beric el britano", publicada entre 1894 y 1896 ,

«Es...grato creer que con la sangre sajona, danesa y normanda en nuestras venas, todavía mantenemos una gran mezcla con la de los valientes guerreros que combatieron tan valerosamente contra César y que se rebelaron con Boadicea en un esfuerzo desesperacio para librarse del opresivo dominio de Roma" (nd:v1).

Las estatuas erigidas a Boadicea en Inglaterra y a Vercingetorix en Francia testimonian el poder de esas figuras cuasi-históricas y su papel en los mitos nacionalistas que sustentaron la expansión imperial de Gran Bretaña y Francia.

Creados como los primeros pueblos de Europa occidental con nombre propio, esta familiar imagen "céltica" no es, ni ha sido nunca, propiedad exclusiva de los arqueólogos en el sentido en que lo fue el "Pueblo Campaniforme". Más bien la palabra tiene resonancia y significado para la mayoría de los europeos occidentales, implicando una unidad que, a pesar de los intentos para desenmarañar las definiciones específicas a las que podía aplicarse (p. ej. Renfrew, 1987: 225), representa una mezcla fluida dentro de la cual los diferentes significados se desbordan y se entretejen inextrincablemente.

Pero éste es un pasado creado a nuestra propia imagen (Merriman, 1987): porque la Edad del Hierro era percibida como "céltica" poca falta hacía que la viéramos como el período que realmente era. La Edad del Hierro, tomando prestada la frase de Shils, había sido convertida en "céltica" en el curso del tiempo pasando de lo anticipado, a lo inevitable, y de ahí a lo aceptable.

$\mathrm{El}$ "hecho" de que el período fuera "céltico" facilita unos medios "objetivos" para examinar el registro arqueológico (Clarke, 1972; Crumley, 1974). Como una sociedad y religión "célticas" (p. ej. Cunliffe, 1983, 1984 a y b; Hingley, 1984; Wait, 1985) son invocadas para explicar el registro arqueológico, ese registro nunca se usa para poner en duda las suposiciones subyacen- 
tes. El diálogo es unidireccional. El contexto "céltico" no sólo es poderoso porque es emotivo, si no porque es total. Le permite a uno, simultáneamente, describir la estructura de las creencias y explicar las minucias del registro arqueológico. El contexto "céltico" ha negado la diferencia durante la Edad del Hierro: porque el pasado es "céltico", no ha hecho falta buscar evidencia arqueológica sobre la naturaleza de la vida y de la sociedad durante ese período. En lugar de ello, la arqueología simplemente ha servido para ilustrar el libro de historia "céltica".

Discutir la percepción de los estudiantes de que la Edad del Hierro es aburrida es poner en cuestión la Edad del Hierro "céltica". Sostenemos que la "celticidad" es ilusoria. La "sociedad céltica" nunca existió (Collis, 1985). Lo que es peor, una arqueología de los Celtas es, en nuestra opinión, una arqueología fundamentalmente racista.

Los relatos familiares de la organización social y religión "célticas" están sacados de una selección de fuentes literarias diversas en cuanto a su lugar, tiempo y contexto originario. Cada una de ellas, individualmente, requiere una interpretación cuidadosa en su propio contexto, antes de que sea ni siquiera considerada la posibilidad de combinar fuentes tan ampliamente diferentes. El "celtismo" o la "celticidad" dependen de una forma platónica, una esencia constante a pesar del cambio en la apariencia y las circunstancias externas; una esencia que, en última instancia, descansa en conceptos nacionalistas y racistas decimonónicos de etnicidad.

Sin embargo no es precisamente la "celticidad" de una Edad del Hierro "celta" la que sirve para reforzar la noción de un pasado familiar. La idea de una continuidad linear tanto dentro de la Edad del Hierro como a partir de ella tiene por resultado una visión del período como una proyección hacia atrás del pasado más reciente (Hill, en prensa). Esto asigna una posición de privilegio, como fuente de analogía, a la historia europea posterior. Desde el inicio de la arqueología de la Edad del Hierro, el propósito de extender hacia atrás la historia de los pueblos europeos conocidos es particularmente clara en los paralelos eurocéntricos usados para explicar el período. Las analogías con la Europa feudal de la Alta Edad
Media (veáse claramente en términos tales como Furstensitz y Adelsitz) pueden ser usadas sin escrúpulo, a menudo con la suposición explícita de que Europa era esencialmente la misma antes y después del período romano. Esta posición ha sido adoptada explícitamente por Peter Wells (1984: 198, 205), e implícitamente por muchos otros autores. Suposiciones similares toman en consideración una "continuidad" en las estructuras de parentesco entre la Alta Edad Media y la Edad del Hierro en Europa (Gosden, 1985). Otro tanto cabe decir de la marcada ausencia del uso de paralelos etnográficos en la arqueología de la Edad del Hierro a pesar de su uso frecuente en otras ramas de la Arqueología. El hecho de que no deba sentirse necesidad de utilizar tales recursos, y la reacción con la que se han encontrado los pocos usuarios (Gosden, 1985; Reynolds, 1985) enfatizan, de nuevo, la profundamente enraizada suposición de una Edad del Hierro específicamente europea, cuyos partidarios tienen dificultad en reconocer incluso la posibilidad de un pasado radicalmente diferente.

De igual importancia para limitar nuestra comprensión de la Edad del Hierro es el intento tanto de escribir Arqueología como Historia ("pseudo-historia" étnica "con cerámica») cuanto la general atracción del texto escrito sobre la inferencia arqueológica. Los relatos escritos se perciben como más verdaderos en situaciones donde aplican directamente un sentido ampliado que en situaciones donde no lo hacen. Los relatos escritos son, a la vez, más atractivos, inmediatos y familiares, ofreciendo una intimidad y detalle que la Arqueología, supuestamente, no puede ofrecer. Desde este punto de vista, la Edad del Hierro es afortunada al estar en el "Umbral de la Historia". A pesar de sus limitaciones, los textos escritos proporcionan ideas que la arqueología sucia por si misma no puede tener la esperanza de facilitar (Harding, 1974: 4). El resultado es una mala utilización de las fuentes escritas posteriores y de nociones generalizadas respecto a los "Celtas" y a la «sociedad céltica"; es una opción atractiva y fácil. Implica una escasa necesidad de desarrollar, o utilizar de forma completa, el registro arqueológico, y ni siquiera tal necesidad es clara para los practicantes de esa pseudo-arqueología. En una situación semejante, la búsqueda de similarida- 
des "célticas", la suposición de una "sociedad céltica" y los argumentos en favor de continuidades a largo plazo, pueden concebirse como un intento de mantener la Edad del Hierro, como un umbral de la Historia, y de evitar sumergirla en la Prehistoria. Un aspecto curioso de este historicismo es que, en ninguna otra parte de la arqueología europea, los practicantes de la arqueología "fantástica" están tan próximos a los practicantes de la "arqueología ortodoxa". Los primeros son capaces de escribir trabajos que se asemejan a los de los académicos "ortodoxos". La diferencia entre unos y otros reside, simplemente, en que la aceptación elemental de los principios de correspondencia y coherencia (Hodder, 1991: 100) permite que estos últimos sean evaluados críticamente.

Àsí las suposiciones silenciosas y generales a partir de las cuales la Edad del Hierro ha sido percibida han borrado incluso la posibilidad de un tipo diferente de Edad del Hierro. Irónicamente, podemos concluir que una rama de la Arqueología que es considerada a menudo como ateórica y muy empírica ha sido demasiado teórica. Ideas preconcebidas y suposiciones no revisadas han sobredeterminado nuestros puntos de vista sobre el período, y han creado un visión muy pesimista de las propias capacidades de la Arqueología para dar luz sobre todos los aspectos del pasado.

\section{UNA EDAD DEL HIERRO DIFERENTE}

Nuestro argumento, perfilado en la primera parte de este artículo, enfatiza la necesidad de un acercamiento más crítico y reflexivo a nuestras silenciosas ideas preconcebidas, y reclama un enfoque más contextual tanto de las exiguas fuentes literarias como del rico registro arqueológico. Esto significa poner un mayor énfasis en el registro arqueológico en nuestro encuentro con la diferencia del pasado. Sin embargo no son exactamente nuestras suposiciones más generales sobre el período las que crean un cuadro familiar de la Edad del Hierro, sino también nuestras acríticas ideas preconcebidas sobre los detalles de la Arquẹología que se fijan en un registro doméstico y fuertemente domesticado. Generalmente hemos percibido nuestros datos como no problemáticos, asumiendo que los funerarios y, especialmente, los domésticos pueden hablar por si mismos (Champion, 1987: 106). Esto queda reforzado en parte por el acercamiento general al período, particularmente en Gran Bretaña, mediante una acusada división entre un registro arqueológico monumental para el Neolítico y la Edad del Bronce y otro doméstico para la Edad del Hierro. También ha sido importante la generalizada suposición de que lo cotidiano es indiscutible, pasivo $\mathrm{y}$ funcional.

Un registro arqueológico doméstico, por lo general, se percibe a la vez como accesible, comprensible y familiar. Puede concebirse como el producto de gentes como nosotros $(0$, al menos, como nuestros recientes [imedievales!] antepasados campesinos) que quizás vivieron en casas de forma diferente y usaron vasijas de forma diferente, pero que no eran diferentes en sus necesidades y perspectiva. Esta identificación asigna el papel de superstición y folclore a lo que no resulta familiar en la cultura campesina europea, lo cual sería visto en situaciones noeuropeas como ritual, simbólico, y como expresión de una cosmología diferente. La reconstrucción de la dieta, la subsistencia y la organización espacial a partir de "basura" y agujeros de poste no es problemática. En este mundo conocido de familias simples y ampliadas, con sus fosos y cercas para encerrar animales y para dejarlos fuera, lo diferencial del pasado resicle en el modo como esas unidades están organizadas (Hill, 1993b). Es precisamente la estructura social y económica pasada la que es distinta, una sociedad tribal o feudal más que una compleja sociedad estatal. Los dirigentes pueden cambiar, los romanos llegan y se van, pero la gente común sigue siendo esencialmente la misma. La gente de la Edad del Hierro se limita a responder representando sencillamente su papel. Además muchas explicaciones, especialmente de orden y de lugar central, ofrecen paisajes y sociedades extrañamente despobladas. Son los asentamientos y los sub-sistemas los que interactúan, se comunican y cambian, no los habitantes (Barrett, 1989).

¿Pero es el registro arqueológico de la Edad del Hierro tan sencillo como tales reconstrucciones nos harían creer? ¿Son Little Woodbury, Danebury, Hodde, Manching o Aulnat tan domesticados o familiares como nos gustaría 
pensar? ¿No son, quizás, a su manera tan diferentes y "otros" como el Neolítico? Tomemos, por ejemplo, la clásica granja tipo Little Woodbury (Bersu, 1940). Tales granjas nos son, quizás, muy familiares gracias a numerosos informes de excavación, relatos en los manuales, fotografias y películas de modelos y reconstrucciones, en especial los puntos de vista casi obligatorios de Butser. Los rasgos de tales asentamientos son tan familiares que están fuera de discusión. Las casas redondas, y los fosos de cierre tienen funciones obvias, y aunque las justificaciones para interpretar cuatro postes y pozos como dispositivos de almacenamiento se repiten normalmente, es más para completar lo que todos sabemos y para estar de acuerdo en que lo son. iAdemás podemos invocar experimentos científicos para probarlo! Se ha sentido poca necesidad de comprender la estructura del registro arqueológico de la Edad del Hierro cuyo gran volumen, comparado con el de períodos más antiguos, crea una falsa sensación de seguridad representativa. Se ensayan explicaciones funcionales simples pero faltan las cuestiones fundamentales. Así, al discutir la organización espacial, la disposición de la basura, las actividades artesanales o la economía, asumimos una relación directa, totalizante, entre la Arqueología y las realidades sociales pasadas. El resultado es la percepción de una esfera doméstica indiscutible en la vida diaria (Barrett, 1989).

Este registro doméstico, simplemente porque es doméstico y no obviamente ritual, se considera no problemático. Pero recientes revisiones del registro están revelando multitud de problemas (p. ej. Bowden y McOmish, 1987, 1989; Boast y Evans, 1986; Hill, 1989; Cumberpatch, 1991). Cuando se combinan con estudios etnográficos del espacio y la basura (p. ej. Hodder, 1982; Moore, 1986; Bourdieu, 1990), desafían nuestras suposiciones racionales y funcionales, la noción de un registro simplemente representativo y, en última instancia, las categorías de sentido común que alegremente asumimos como universales. Una alternativa a tal enfoque de "sentido común» es una "arqueología de contraposición" (3) que busca la diferencia en nuestro pasado.

(3) Nota de la traductora: "contrastive" en el texto original.
Un ejemplo de esto es la gran cantidad de hallazgos en asentamientos de tipo Little Woodbury, residuos, parecería, de la familiar vida diaria. ¿Pero puede verse la basura como una categoría amorfa y sencilla?

Una parte muy pequeña del desperdicio producido en un sitio llega a incorporarse en algún momento, al registro arqueológico. La mayoría de los hallazgos de un asentamiento tipo Little Woodbury proceden de pozos de almacenamiento en desuso. Estimaciones simples relativas a la frecuencia con la que los pozos pudieron haber sido abiertos, y a las cantidades totales de material depositadas cada año, son sorprendentemente escasas (Hill, 1989). Usando la década de vida estimada para un pozo de almacenamiento (Cunliffe, 1984a: 557), durante la Edad del Hierro Media, un pozo es rellenable aproximadamente cada cinco años en Gussage Alli Saints y Winnall Down, y entre cuatro y cinco anualmente en Danebury (Hill, 1993: 10). Las densidades de hallazgos son igualmente muy bajas: $1.3-0.6$ bordes se perdieron al año en Winnall Down (Hill, 1989). Esto sirve para recalcar lo reducidos que son nuestros aparentemente grandes conjuntos de hallazgos de la Edad del Hierro.

La deposición en contextos arqueológicamente recuperables no era un acontecimiento diario, ni anual. Esto ha sido reconocido por Maltby (1985: 55), que ha defendido, usando analogías etnográficas, que el enterramiento deliberado de grandes cantidades de desechos de matanza (del tipo que es común en pozos y fosos) estaba asociado probablemente con ocasiones especiales y festejos. Todavía invoca argumentos funcionales para sugerir por qué tales concentraciones se encontraron en pozos periféricos y fosos de cierre en Winnall Down, principalmente la necesidad de depositar la basura fétida lejos de las áreas donde se vive, aunque no hay una razón a priori por la cual eso deba ser así (Hodder, 1982: 155-167). Así grandes cantidades de restos de matanza, resultado probablemente de festividades especiales, fueron vertidas en pozos y fosos cuyo relleno no era un acontecimiento diario. Era un suceso inusual, si no un evento especial, dada la importancia del almacenamiento en los yacimientos de Wessex y la presencia de humanos, animales y otros «depósitos especiales" (Cunliffe, 1983: 157) en 
casi un $25 \%$ de los pozos. El reconocimiento y la interpretación de tales depósitos son controvertidos, aunque tal escepticismo tiene más que ver con nuestras expectativas de una Edad del Hierro familiar y domesticada. Tomado en su conjunto, el patrón que adoptan los depósitos especiales y su propia presencia sugieren que los contenidos de los pozos no son «basura normal" (Hill, 1993a, b).

Esto tiene importantes implicaciones, en cuanto desafia la correlación directa de los hallazgos con las actividades económicas o sociales pasadas. Lo que es más importante destruye la idea de un registro doméstico seguro, familiar, esencialmente moderno. Dicho francamente, la gente estaba haciendo algo «bastante extraño" con sus pozos durante la Edad del Hierro en Wessex, algo que es comparable (en términos generales) con la "rareza" de la deposición neolítica. Tales observaciones resaltan la necesidad de reconsiderar el registro arqueológico de la Edad del Hierro, reconociendo que la gente de esa época no era como nosotros. No podemos seguir tratando el registro como si no fuera problemático, y tenemos que dejar de aislar lo "otro" (restos humanos) como "ritual", o de justificar lo menos descaradamente "otro" (animales y "depósitos especiales"), reconociendo en cambio las implicaciones que esos depósitos tienen en relación con la aparente "basura normal" encontrada en contextos similares. Este estudio describe específicamente la situación durante la Edad del Hierro en el sur de Inglaterra, y aunque los detalles precisos es poco probable que se repitan en otras partes, parece muy probable que estudios críticos parecidos realizados en otras partes de Europa revelen un pasado igualmente diferente a partir del que ha sido establecido por la "sabiduría heredada".

Puede ser un ejemplo la discusión y debate durante los últimos cincuenta años que ha tratado de demostrar que los Oppida del $\mathrm{La}$ Tène Final son ciudades y cuadran con cualquier definición de ciudad que se defendiera. Al poseer las primeras ciudades de Europa, los Celtas eran situados en una posición ancestral (un concepto que discutiremos más abajo) en relación con los pueblos posteriores de Europa. Por muy extraños que esos grandes sitios cercados pudieran, en principio, parecer eran representados simplemente como versiones de ciudades medievales amuralladas, el lugar del artesanado y la producción en masa de bienes para el campo que los rodea. Tales conclusiones son esbozadas en ausencia de estudios amplios sobre, por ejemplo, el papel jugado por los asentamientos abiertos en la extracción y fundición de las menas metálicas o de la producción cerámica (Cumberpatch, 1991); sin embargo crean un clima conveniente para una historia evolutiva de la Civilización Europea. A muchos especialistas de la Edad del Hierro europea parece importarles poco que las raíces de esta historia hayan sido ampliamente atacadas por antropólogos y arqueólogos que trabajan sobre el Neolítico y la Edad del Bronce, puesto que, para esos especialistas, la Edad del Hierro céltica sigue siendo la flor más delicada de la Europa Bárbara.

Una explicación del abismo entre la perspectiva arqueológica sobre la Edad del Hierro y sobre el Neolítico/Edad del Bronce es el contraste entre un registro ritual "extraño" y otro doméstico «normal». Ha sido mucho más fácil discutir ritual, simbolismo, ideología y poder a partir de los datos monumentales de los períodos citados en segundo lugar que a partir del registro "doméstico" de la Edad del Hierro. El reconocimiento del espacio doméstico "como un texto" y del componente activo de la actuación humana (p. ej. Barrett, 1988; Barrett et alii, 1991; Bourdieu, 1977, 1990; Hodder, 1986, 1987; Moore, 1986), permite (y, realmente, demanda) un nuevo enfoque que evite la mutilante división entre lo ritual/lo secular y lo doméstico/lo no-doméstico y contemple el registro arqueológico de una forma que una indisolublemente lo ideal y lo práctico. Esto significa concebir la cultura material como un elemento activo en las relaciones sociales, y no como un simple reflejo de las mismas, y como un elemento crítico en la construcción de una realidad muy diferente de la que nos es propia. Los pozos y fosos no son contenedores convenientemente vacíos y neutrales en los que se encuentran los conjuntos faunísticos y cerámicos, sino que ellos mismos eran parte de un texto espacial simbólicamente constituido. Wessex pudo ser excepcional por sus pozos, pero, sea en Little Woodbury, Assen- 
delver, Stradonice, Liptovska Mara o Hodde, no deberíamos tratar nuestro registro relativo a los asentamientos con autocomplacencia. Puede que no fuera ni tan familiar, ni tan doméstico como suponemos. La esfera de lo cotidiano no carece de problemas, es el problema.

Al poner en duda la cómoda división entre lo sagrado y lo profano, rechazamos la noción de una Religión Céltica que pueda ser comprendida a partir de un puñado de mitos y leyendas entresacados de las prácticas religiosas eclécticas del Imperio Romano y los registros de leyendas hechos por los monjes cristianos muchos cientos de años después de la construcción de los primeros oppida. ¿Por qué a fines del siglo II A. C. resulta importante cercar no sólo ciertos asentamientos sino también algunos sitios rituales (Viereckschanzen)? ¿Por qué algunos de los más tardíos, como Gournay, contienen abundantes depósitos extraños y deliberados, mientras otros, como Msecke Zehrovice y Markvatice, son tan estériles que casi son anónimos? En tanto que es improbable que un reciclado sin fin de un puñado de textos escritos resuelva tales cuestiones, es posible que la consideración de nociones que impliquen el uso simbólico del espacio y la manipulación significativa de la cultura material puedan proporcionar ideas inesperadas.

Quizás los estudios sobre la Edad del Hierro son aburridos porque la Edad del Hierro era realmente aburrida. Hemos buscado historias emocionantes, concentrándonos en el contacto mediterráneo, los guerreros, la migración de tribus, las tumbas ricas, los Celtas y los oppida. Pero la mayoría de Europa durante ese período estaba compuesta esencialmente por sombrías comunidades agrarias. Cuando nos centramos en tales comunidades, en su interacción y contacto, todavía subsiste el peligro de que nuestras explicaciones recurran a relatos que contemplan a las Sociedades como unidad de análisis, como una serie de fuerzas determinadas con su propia vida. Las Sociedades no existen independientemente de sus miembros, dependen de las acciones de la gente para su reproducción y cambio mediante la forma como los humanos ocuparon rutinariamente su mundo y actuaron sobre él en el tiempo y en el espacio, en la vida cotidiana (Barrett, 1988, 1989; Barret et alii, 1991).

\section{CONCLUSION}

En este artículo hemos defendido que la arqueología de la Edad del Hierro necesita volverse más "prehistórica" (es decir, postpro)cesual) en cuanto a su naturaleza. Las suposiciones dominantes, y los prejuicios que determinan cómo contemplamos tradicionalmente nuestro período han creado una visión en gran parte historicista del pasado donde la analogía con las situaciones posteriores, escritas, ha sido siempre privilegiada respecto a los intentos de usar el registro arqueológico en sí mismo. Ello ha dado lugar a una visión muy pesimista de lo que puede decirse a partir de él. La arqueología del Neolítico y de la Edad del Bronce, sin las trabas de una visión "histórica", ha tenido que estar más abierta a sus datos, a manejar cada parte del registro para todos los aspectos de la cultura y la sociedad pasadas no sólo los escalones inferiores de la "Escalera de Inferencia" de Hawkes (1954).

La arqueología de la Edad del Hierro ha producido un pasado más familiar que el ofrecido por la Prehistoria más antigua, y miedo a que, saltando hacia la Prehistoria, la pérdida de la inocencia tenga como resultado erlebnis: una experiencia como acontecimiento aislado de un contexto significativo, una información desconectada (cf. Benjamin, en Shanks y Tilley, 1987: 18-19). Al subrayar lo "otro" podría existir el peligro de una pérdida de significado $o$, al menos, el estancamiento de ciertas ramas del estructuralismo, pero sólo si dejamos de reconocer que no vivimos dentro de un horizonte cerrado, ni único. Esto excluye el ideal de una aplicación total del pasado, pero implica una tensión entre lo propio y lo ajeno; una paradoja de otredad (4) (Ricoeur, 1981: 61-62). Hay peligro de "pérdida de sentido" si lo otro, lo diferente se subraya en exceso. Sin embargo este difícilmente parece un problema para los estudios de la Edad del Hierro donde no puede evitarse la fuerte tradición eurocéntrica.

A este respecto, nuestra paradoja de otredad es mucho más intrigante y compleja. La gente de la Edad del Hierro (no «los Celtas») compartieron diferentes cosmologías, percepciones del espacio, y lo que es más importante,

(4) Nota de la traductora: "otherness" en el texto oríginal. 
subjetividades (Hill, 1993b). Pero, al proyectar nuestro ideal familiar, eurocéntrico, afrontamos un pasado en el que parece haber objetos familiares; ciudades, monedas, granjas, y campos, y una falta de lo abiertamente ritual con lo que nos tropezamos en los períodos más antiguos (en lugar de ello, tenemos una "Religión Céltica" de la que normalmente se habla en relación con la de Grecia y Roma). Pero esos rasgos están en fase de llegar a ser. Esos rasgos podían parecer familiares, pero la gente de la Edad del Hierro vivía en sus propios mundos de significado, y la semejanza es engañosa. Esto sugiere que tenemos que concebir situaciones donde tales rasgos puedan ser organizados en un mundo muy distinto.

Para estar abiertos a la posibilidad de una Edad del Hierro diferente necesitamos ser tan críticos con la complaciente atribución de privilegio a unas analogías con nuestro desarrollo cultural posterior (p. ej. Gosden, 1985) establecidas como si fueran más relevantes que las analogías con etnografias específicas, como con las generalidades extraidas de ellas. Las últimas pueden actuar como un desafio, una incitación que nos ayude a reconocer en nuestros datos patrones que no habíamos esperado que estuvieran allí. No tienen que emplearse para hundir la Edad del Hierro bajo generalidades producidas a partir de la Etnografia. Precisamente no se trata de escribir el mismo pasado u otro, el nuestro o el suyo. Es posible concebir una Europa que no es nuestra Europa.

Concebir una Edad del Hierro distinta es desafiar la naturaleza genealógica de nuestros estudios. En una genealogía buscamos en el pasado lo que es nuestro, ya que esta posesión es la que da valor al pasado. Como genealogía de la Europa moderna, la arqueología de La Edad del Hierro ha buscado los orígenes de lo que es distintivo de esa Europa en el Primer Milenio A. C. y, consiguientemente, ha producido visiones del período que son, en gran parte, fantasías contemporáneas. Michel Foucault ha ofrecido una genealogía diferente que investiga críticamente los orígenes y desarrollo de nuestras suposiciones europeo-occidentales más básicas. Al criticar nuestra comprensión de sentido común del pasado, criticamos las categorías de pensamiento cuyos orígenes estamos intentando comprender (Rowlands, 1987: 746). Este es un proceso doble al implicar una crítica de las suposiciones actuales que moldean un pasado familiar y un reconocimiento positivo de la diferencia del pasado, mediante la utilización de todas las ventajas de nuestra amplia base de datos sobre la Edad del Hierro. El resultado será una historia crítica de la arqueología de la Edad del Hierro, y un acercamiento crítico a las prácticas cotidianas durante ese período que son accesibles a través del registro. Así, resaltando la diferencia de la Edad del Hierro, conseguimos tanto una comprensión más completa de lo que sucedió en el pasado, como desafiar lo que está sucediendo en el presente al subvertir la legitimidad de esas ideologías y nociones contemporáneas que suponemos que son verdades universales.

\section{BIBLIOGRAFIA}

BARRETT, J. (1988): "Fields of discourse: reconstituting a social archaeology". Critique of anthropology, 7.3: 5-16.

- (1989): "Food, Gender and Metal: questions of social reproduction". En R. Thomas and M. L. S. Sorenson (eds.): The transition from Bronze Age to Iron Age in Europe. B.A.R. Intern. Ser. 483: 304-320. Oxford.

BARRETT, J.; BRADLEY, R. AND GREen, C. (1991): "Landscapes, Monuments and Society: The Archaeology of Cranbourne Chase». Cambridge University Press. Cambridge.

BaUman, Z. (1978): "Hermeneutics and Social Science". Hutchinson. London.

BERSU, G. (1940): «Excavations at Little Woodbury. Wiltshire, Part. 1". Proceedings of Prehistoric Society, 6: 30111.

BOAST, R. AND EVANS, C. (1986): “The transformation of space: two examples from British prehistory". Archaeological Review from Cambridge, 5.2: 193-203.

Bourdieu, P. (1977): "Outline of a Theory of Practice". Cambridge University Press. Cambridge.

BowDEN, M. AND MCOMish, D. (1987): "The Required Barrier". Scottish Archaeological Review, 4: 76-84.

- (1989): "Little Boxes: more about hillforts". Scottish Archaeological Review. 6: 12-16.

BRADLEY, R. (1984): “The Social Foundations of Prehistoric Britain". Longworth. London.

- (1986): "Modernist fantasies in prehistory". Man, 21: 747-8.

BURL, A. (1981): “Rites of the Gods». Dent. London.

Champion, T. (1985): "Written sources and the study of the Iron Age". In T. Champion and V. Megaw (eds.): "Settlement and Society. Aspects of West European Prehistory in the First Millenium BCm. Leicester University Press. Leicester: 9-22. 
- (1987): "The European Iron Age: Assessing the state of the art". Scottish Archaeological Review, 4: 98-107.

Chapman, M. (1992): "The Celts: The Construction of a Myth". Macmillan Press. London.

ClARKE, D. (1972): "A provisional model of an Iron Age society and its settlement systems". In D. Clarke (ed.): Models in Archaeology, Methuen. London: 801-869.

- (1973): "Archaeology: The Loss of Innocence». Antiquity, 47: 6-18.

Collis, J. (1984): “What do we want to know?». In A. Cahen-Delhaye, A. Duval, G. Leman-Delrive and P. Leman “Les Celtes en Belgique et dans le Nord de la France. Revue du Nord/A.F.E.A.F: 283-285.

- (1985): "Review of Danebury: An Iron Age Hillfort in Hampshire". Proceedings of Prehistoric Society 51: 348349.

Crumley, C. (1974): “Celtic Social Structure». Anthropological Papers. Museum of Anthropology. University of Michigan. 54. Michigan.

Cumberpatch, C. G. (1989): "Ideological impacts on the archaeological record". Newsletter of the Archaeological Formation Processes Study Group, 4: 6-7.

- (1991): "The Production and Circulation of late Iron Age Slip Decorated Pottery in Central Europen. Unpublished $\mathrm{Ph}$. D. thesis. Sheffield.

Cunliffe, B. (1983): “Danebury: Anatomy of an Iron Age Hillfort " Batsford. London.

- (1984a): «Danebury: An Iron Age Hillfort in Hampshirem. CBA Research Reports, 52 CBA. London.

- (1984b): "Iron Age Wessex: Continuity and Change" In B. Cunliffe and D. Miles (eds.): "Aspects of the Iron Age in Central-Southern Britain". University of Oxford, Committee for Archaeology. Monograph 2, Oxford: 12-43.

DenNell, R. (en prensa): "Archaeology and Ethnicity: Lilliput revisited". Scottish Archaeological Review.

GosDEN, C. (1983): «Gifts and Kinship in Early Iron Age Europe". Man, 20: 473-494.

HARDING, D. W. (1974): The Iron Age in Lowland Britain. London.

HAWKES, C. F. C. (1954): "Archaeological theory and method: Some suggestions from the Old World". American Anthropologist, 36: 155-168.

Henty, G. A. (1894-1896): "Beric the Britain: A Story of the Roman Invasion".

Hill, J. D. (1989): "Rethinking the Iron Age». Scottish Archaeological Review, 6: 16-24.

- (1993)a: «Ritual and Rubbish in the Iron Age of Wessex: A study of the Formation of a Particular Archaeological Record". Unpublished. Ph. D. Thesis. Cambridge.

- (1993)b: «Can we recognise a different European past? A contrastive archaeology of later prehistoric settlements in southern England». Journal of European Archaeology, 1: 57-75.

Hingley, R. (1984): "Towards social analysis in Archaeology: Celtic society in the Iron Age of the Upper Thames Valley". In B. Cunliffe and D. Miles (eds.): "Aspects of the Iron Age in Central-Southern Britain", University of
Oxford, Committee for Archaeology. Monograph 2, Oxford: $72-88$.

HODDER, I. (1982): "Symbols in Action" Cambridge University Press. Cambridge.

- (1986): "Reading the Past". Cambridge University Press. Cambridge.

- (1987): "The meaning of discard: Ash and domestic space in Baringo". En S. Kent (ed.): "Method and Theory in Activity Area Research". Columbia University Press. New York: 424-448.

- (1991): "Interpretative Archaeology and its role". American Antiquity, 56: 7-18.

MALBEY, M. (1985): "Patterns in faunal assemblage variability". En G. Barker and C. Gamble (eds.): "Beyond Domestication in Prehistoric: Europen. Academic Press. London, New York: 33-74.

Merriman, N. (1987): "Value and Motivation in Prehistory: the evidence for "Celtic'spirit". En I. Hodder (ed.): "The Archaeology of Contextual Meanings". Cambridge University Press. Cambridge: 111-116.

Miles, D. (1986): "The Iron Age». En G. Briggs, J. Cook and T. Rowley (eds.): "The Archaeology of the Oxford Region". Oxford University Department of External Studies. Oxford: 48-57.

Millett, M. (1990): "The Romanization of Britain". Cambridge University Press. Cambridge.

MOORE, H. (1982): "The interpretation of spatial patterning in settlement residues". In I. Hodder (ed.): "Symbolic and Structural Archaeologym. Cambridge University Press. Cambridge: 74-79.

Moore, H. (1986): "Space. Text and Gender". Cambridge University Press. Cambridge.

RENFREW, A. C. (1987): "Archaeology and Language". J. Cape. London.

REYNOLDS, P. J. (1985): "Iron Age Agriculture Reviewed". C.B.A. Forum Group 12. Salisbury.

RICOEUR, P. (1981): “Hermeneutics and the Human Sciences". (J. B. Thompson, Ed.) C.U.P. / Editions de la Maison des Sciences de l'Homme. Cambridge and Paris.

Rowlands, M. (1986): "Modernist fantasies in Prehistory". Man, 21: 743-746.

- (1987): "The concept of Europe in Prehistory». Man, 22: 558-559

Shanks, M. AND TIlley, C. (1987): “Reconstructing Archaeology". Cambridge University Press. Cambridge.

SHILS, E. (1981): “Tradition». Faber. London.

TAYLOR, T. (1991): "Celtic Art". Scottish Archaeological Review, 8: 129-133.

Thомas, J. (1990): "Same, Other, Analogue; Writing the Past". In F. Baker and J. Thomas (eds.): "Writing the past in the present". St. David's University College. Lampeter: 18-23.

WAIT, G. (1985): Ritual and Religion in Iron Age Britain. B.A.R. Brit. Ser. 149, Oxford.

Wells, P. (1984): "Farms, Villages and Cities". Cornell University Press. Cornell. 